\title{
The Consideration of Meta-Abilities in Tacit Knowledge Externalization and Organizational Learning
}

\author{
Jyoti Choudrie \\ School of Information Systems, Computing and Mathematics, Brunel University, Uxbridge, \\ Middlesex, UK, jyoti.choudrie@brunel.ac.uk \\ Mohamad Hisyam Selamat \\ Faculty of Accountancy, Universiti Utara Malaysia, Sintok, Kedah, Malaysia \\ hisyam@uum.edu.my
}

\begin{abstract}
This research is concerned with studying the elements that can encourage staff members to contribute inputs for learning-based systems development. To achieve this aim, this research developed a conceptual framework based on the concepts of meta-abilities and tacit knowledge externalization and sharing. Meta-abilities, in turn, are developed by using the elements of understanding organizational roles, internal strengths, formal and informal discussions and rational discourse. The processes undertaken in the novel conceptual framework of this research will ensure that organizational IS are subject to continual reexamination and modification. By internalizing a system's operations, individuals can improve actions through better knowledge and understanding - the learning process. The framework is tested using fieldwork experimentation in Malaysia. It is concluded that the future focus when managing information for $O L$ should be toward an individual's meta-abilities development and creating the correct organizational culture and infrastructure that promotes knowledge sharing.
\end{abstract}

\section{Introduction}

Three major issues associated with learning-based systems are continuous system re-examination and modification [1], knowledge externalization and sharing [2], and making tacit knowledge tangible [3]. This is because in previous research, one of the factors that caused the failure of learning-based systems is that the previous frameworks of OL did not address the processing of tacit knowledge, which is deeply rooted in an individual's action, experience, ideals, values or emotions [4]. This research attempts to propose a conceptual framework to identify and discuss these issues and to ease the process of developing learning-based systems. To achieve this aim, this research assumes that there are two main aspects to be considered. These are the ability to externalize and share knowledge and skills, and selfdocumentation. These two aspects can encourage staff members to contribute inputs for learning-based systems development.

To develop staff members' confidence and willingness to contribute inputs for learning-based systems development, this research proposes the concept of meta-abilities. Meta-abilities, in turn, are developed by using the elements of understanding organizational roles, internal strengths, formal and informal discussions and rational discourse. The conceptual framework will be tested by using fieldwork experimentation.

A theoretical overview of OL, tacit knowledge diffusion, meta-abilities and the proposed conceptual framework are firstly dealt with. The research approach and the description of the case study are then presented. Thereafter the success and failure of the fieldwork are discussed in light of the conceptual framework and the lessons learnt are then highlighted. In the final section, the conclusions and suggestions for further research are dealt with.

\section{Conceptual Foundations of Organizational Learning}

To understand how the externalization and sharing of tacit knowledge and meta-abilities can be used to support OL, it is useful to have a fundamental understanding of those concepts. In the following section, this is provided. 


\subsection{The Difficulty in Tacit Knowledge Externalization and Sharing}

Tacit knowledge is not easily externalized due to its transparent and subjective nature [5]. Difficulties appear in expressing or documenting knowledge that appears obvious and natural to one [2]. Further, the difficulties in externalizing and sharing of tacit knowledge are also linked to language, time, value and distance. Alternatively there are factors that prevent individuals from sharing their tacit knowledge or inquiring others for clarification including lack of confidence, anxiety, unwillingness, confusion, and being carried away by strong feelings [6].

The above discussion presents, in general, the main factors for consideration when trying to externalize and share tacit knowledge. Therefore, understanding how to encourage individuals to externalize, share and document their tacit knowledge is important to gain inputs from them.

\subsection{Frameworks in Organizational Learning}

Argyris and Schön [5] define OL as the process of detection and correction of errors. Based upon this understanding, it is argued that organizations learn through individuals, who act as agents for the organizations. However, it is assumed that staff members are willing to interactively learn and change, which is not always the case in a practical situation [6]. Senge [7] defines an LO as an organization "in which you cannot not learn because learning is so insinuated into the fabric of life." However, this aspiration gradually diminishes if there is no teamwork amongst the staff members.

Huber [8] considers four constructs as integrally linked to OL: (1) knowledge acquisition; (2) information distribution; (3) information interpretation; and (4) organizational memory. However, Huber's [8] framework is built on the belief that staff members have self-confidence, a sense of responsibility and feelings of belonging to the company in order to externalize and share their tacit knowledge. As a result, this framework has a potential to fail if there is no commitment from the staff members to support it. To overcome this issue, this research will incorporate the concept of meta-abilities in the learning-based systems developmental framework.

Klimecki and Lassleben [9] conceptualize OL as a communicated-based process where the organization overcomes its previous boundaries of knowledge and ability by allowing its members to share knowledge, interact and influence each other and cope with difficult situations. Combining Huber's [8] and
Klimecki and Lasslebens' [9] perspectives, Nonaka and Takeuchi [10] see OL involving the generation, absorption and sharing of tacit knowledge and they emphasize the importance of interaction amongst people towards the development of OL capabilities. In other words, OL is the process of continued innovation through the creation of new knowledge [10]. It is an ongoing process that takes place as staff members engage in knowledge work [11]. These views illustrate the importance of having continuous IS updates through the medium of communication amongst staff members. However, to enable the communication process, staff members have to be self-confident and be encouraged to talk to others in the workplace. Lack of confidence and anxiety will demotivate an individual from communicating with others and consequently reduce the effectiveness of the framework.

Meso and Smith [1] argue that learning emanates from the iterative process of knowledge externalization and internalization. Externalization occurs when an individual's tacit knowledge is captured as explicit knowledge. Internalization occurs when this captured explicit knowledge is then transformed into another individual's tacit knowledge. In this case, OL occurs at the intersection of tacit and explicit knowledge during the interaction of various staff members, departments or teams in an organization. However, this framework still relies on the ability of staff members to externalize and internalize knowledge.

In summary, the capability to externalize, share and document tacit knowledge is of paramount importance for OL frameworks. This in turn illustrates that staff members should be instilled with that capability. Therefore, at this point it is declared that individual development should become the starting point in an OL-based IS developmental framework. This research intends to use this reasoning to illustrate the role of meta-abilities in OL.

\section{Meta-Abilities Development}

This section goes into more detail regarding the elements that can be used to develop staff members' abilities to externalize, share and document their tacit knowledge. Understanding the ability to externalize, share and document tacit knowledge enables an organization to undertake continuous IS updates and consequently disseminate new insights for learning. The following subsection presents an overview of meta-abilities that will be used as a means for developing staff members' abilities to externalize, share and document tacit knowledge. The subsection 
after that discusses the elements that will be used to develop meta-abilities in this research.

To develop an organization, it has been suggested that competencies should be generic rather than organization specific [12]. Additionally, competencies cannot be usefully specified in terms of neatly identifiable, observable or measurable behaviors. Therefore, competencies should involve increasing self-knowledge and improving "meta-abilities" those personal, acquired abilities which underpin and determine how and when knowledge and skills will be used [12].

Butcher et al. [12] found that there are four metaabilities that are critical in organizational development: (1) cognitive skills; (2) self-knowledge; (3) emotional resilience; and (4) personal drive. The description of each meta-ability is given in Table 1.

Table 1. The description of meta-abilities

\begin{tabular}{|l|l|}
\hline $\begin{array}{l}\text { Meta- } \\
\text { abilities }\end{array}$ & Description \\
\hline $\begin{array}{l}\text { Cognitive } \\
\text { skills }\end{array}$ & $\begin{array}{l}\text { Includes the ability to notice and interpret what is } \\
\text { happening in interpersonal situations; to entertain } \\
\text { multiple perspectives and integrate them; to } \\
\text { envision strategic futures; and to sort and analyze } \\
\text { data. These skills allow organizational members to } \\
\text { "read situations, understand, and resolve } \\
\text { problems." }\end{array}$ \\
\hline $\begin{array}{l}\text { Self- } \\
\text { knowledge }\end{array}$ & $\begin{array}{l}\text { Seeing oneself through another's eyes, knowing } \\
\text { one's own motivations, and values and } \\
\text { distinguishing one's own needs from those of } \\
\text { others. These skills allow organizational members } \\
\text { to consider a range of options in their own } \\
\text { behavior and to make better judgments of what to } \\
\text { do. They allow other skills and knowledge to be } \\
\text { used more flexibly. }\end{array}$ \\
\hline $\begin{array}{l}\text { Emotional } \\
\text { resilience }\end{array}$ & $\begin{array}{l}\text { Includes self-control and discipline; the ability to } \\
\text { use emotion well to cope with pressure and } \\
\text { adversity; and balance feelings about oneself. } \\
\text { These skills allow organizational members the } \\
\text { personal robustness to direct their energies, deal } \\
\text { with intense situations and manage challenges } \\
\text { healthily. }\end{array}$ \\
\hline $\begin{array}{l}\text { Personal } \\
\text { drive }\end{array}$ & $\begin{array}{l}\text { This involves self-motivation and determination, a } \\
\text { willingness to take responsibility and risks. This } \\
\text { helps organizational members to persist, motivate } \\
\text { others and meet targets. }\end{array}$ \\
\hline
\end{tabular}

This research proposes the following elements in order to develop the above meta-abilities: (1) understanding organizational roles; (2) internal strengths; (3) formal and informal discussion and (4) rational discourse. This is because all these elements are more focused upon developing the staff members' communication skills, assertiveness and dealing with conflict, persuading others and managing organizational politics, which are relevant to achieve the objective of this research. The definitions and descriptions of each element are provided in the following subsections.
This research argues that staff members need to understand three fundamental aspects when working in the organizations: (1) personal responsibility; (2) task priority and (3) personal targets $[6,12,13]$. As this understanding promotes the judicious use of accumulated experience, it is beneficial when considering learning activities and was therefore adopted in this research.

This research proposes eight internal strengths that should be instilled to staff members in order to develop meta-abilities and thus establish a learning environment. These eight internal strengths were selected because they enable the use of knowledge and skills in an effective manner $[4,12,14]$.

The first internal strength that is proposed in this research is personal confidence. Personal confidence is a self-belief in undertaking and accomplishing organizational tasks [15]. As one of the elements that prevent staff members from externalizing and sharing their tacit knowledge is lack of confidence [2,6], this element should be emphasized when understanding an OL framework. The second internal strength proposed in this research is observing accepted organizational approaches. By observing accepted organizational approaches, staff members can undertake tasks based upon "the right approach for the right situation" [13]. As this internal strength promotes sharing information with, and obtaining clarification from, other parties, it needs to be emphasized in creating a learning environment [16].

The third internal strength discussed here is undertaking tasks with commitment and selfdiscipline. Without these values, staff members tend to undertake a job hastily and carelessly. This in turn will badly affect the quality of organizational operations. The fourth internal strength is selfawareness. Self-awareness is defined as "an ability to determine the tasks that need to be accomplished at the current time and accomplish the determined tasks according to an accepted organizational approach" [12]. In other words, it is related to the phrase "do the right things at the right time." Self-remembrance is the fifth internal strength. In this research, selfremembrance is defined as "the value that requires staff members to mind their actions when undertaking a task so that it can be accomplished effectively and to remember that through their effective actions the company can achieve a good profit and consequently give them a good salary and bonus" [13]. The sixth internal strength is compassion. Being equipped with this value, staff members can trust each other and consequently neutralize the feeling that prevents them from sharing information with other members.

The seventh internal strength is sincerity. Every staff member must have a feeling that he/she works 
for the sake of the company and for fulfilling his/her responsibility to the company. Sincerity can motivate staff members to work collectively and harmoniously in the workplace. Finally, staff members must have the willingness to change whenever the need arises. This is due to rapid changes in the organizational life and business environment.

Another element that is proposed by this research when developing the meta-abilities is the ability to conduct formal and informal discussions within the organization. This is because staff members face various tasks in daily activities - routine, non-routine, official and unofficial [17]. Formal approaches are procedures such as meetings, progress reports and performance evaluation reports (ibid). Informal approaches include dialogue, face-to-face interaction, corridor meeting, lunch table chats and coffee/tea table chats (ibid). Through good communication, learning and teaching activities can be undertaken actively amongst staff members. Therefore, this value should be emphasized in order to create effective OL framework.

A rational discourse can legitimize the selection of a design ideal because it ensures that the arguments of all interested parties are heard, that the choice results in an informed consensus about the design ideal, and the formal value choice is only made by the force of the better argument [18]. These values are critical for developing the above cognitive skills and selfknowledge. In addition, they are able to promote active tacit knowledge externalization and sharing amongst staff members, especially in meetings and dialogue. Therefore, rational discourse should be considered for establishing a platform in an individual's mindset for creating learning environments in an organization.

From the aforementioned discussions, it is declared that the concept of meta-abilities in this research is developed based upon the elements of understanding organizational roles, internal strengths, formal and informal discussion and rational discourse. This is something that prior research such as that by Butcher et al. [12] has not undertaken. Additionally, the concept of meta-abilities in this research is utilized for developing an effective OL framework and not organizational development, as proposed by Butcher et al. (1997). This strategy makes this research unique to that of Butcher et al. [12].

\section{The Conceptual Framework}

Based on the above discussion, it can be learnt that meta-abilities can assist in building a confident and responsible individual [6]. These values, in turn, create these three competencies. First, meta-abilities can create individual influencing skills (ibid). Second, meta-abilities can develop individual sharing attitudes (ibid). Third, meta-abilities can develop inquisitive tendencies (ibid). As the problems of developing OLbased IS are founded on the need to develop an individual's ability to externalize and share of tacit knowledge, as discussed in the previous sections, the meta-abilities, influencing skills, sharing attitudes and inquisitive tendencies (seven competency sets) are the humanistic elements that can be considered.

By practicing the above influencing skills and sharing attitudes, individuals can generate creative ideas (I), actions (A), reactions (R) and reflections (R) $[10,19]$. The terms ideas, actions, reactions and reflections represent forms of activities within an organization. This externalized and shared tacit knowledge can provide synergistic inputs for a continuous development of IS (ibid). However, it must be documented first. This can be achieved by the value of self-documentation, which is also developed by meta-abilities [12]. This is because, due to the development of meta-abilities, the willingness to question implicit assumptions, explore new possibilities and direct energies toward higher standards enables the staff members to be well prepared, using good documented progress reports or working papers (ibid).

Reflecting on the above discussion, it can be determined that individual development becomes the starting point in the OL framework. Additionally, it can be learnt from the previous discussion that understanding organizational roles, internal strengths, formal and informal discussion and rational discourse should become the starting point for the individual development.

The ways in which the above dimensions relate to each other are illustrated in Figure 1. As shown in the diagram, knowledge and meta-abilities strongly influence the way in which an individual interprets, analyses and makes judgments about a given situation. Equivocally, the range of behavioral strategies that the individual will consider is influenced, and so are the actions that he or she ultimately decides to utilize and the ideas he or she ultimately shares. The level and range of influencing skills and sharing attitudes an individual can call upon will determine how well or in what way these ideas, actions, reactions and reflections are taken. It is these individual ideas, actions, reactions and reflections which ultimately provide externalized tacit knowledge for OL-based IS development.

\section{Research Approach}


To identify whether the aforementioned conceptual information is applicable in practice, the following approach was applied. A qualitative approach that allowed this research to obtain understanding on humanistic elements was undertaken [20]. Further, the study has utilized fieldwork experimentation - a faculty in one of the Malaysian higher education institution - to investigate the research question for this research. The research activity consisted of preparing the training module, conducting the training program and collecting data. The module contained the descriptions of meta-abilities and was utilized to instill meta-abilities among the respondents during the training program.

The participants consisted of 11 lecturers and one resource centre officer. The lecturers were selected as they were the critical group in ensuring the smooth operation of the faculty; therefore the learning process was emphasized on them. Alternatively, the resource centre officer was selected because she was critical in the information processing; therefore was relevant to study the impact of the framework in information processing and consequently learning process.

Two months after the training session, face-to-face interviews were conducted. A two-month period was allocated to enable progress review process and the participants to understand and utilize the elements that were discussed in the program. A face-to-face interview was utilized since it provided flexibility in the questioning process, control of the interview situation and provide the opportunity of obtaining additional information, such as the background information or natural reactions [21]. The interviews were tape-recorded and transcribed on the same day. This approach was utilized to ensure that all the information and any further details that were imperative for this research were recorded and not missed out [22]. The data were analyzed by using manual analysis due to the small number of participants.

\section{Describing the Case Study}

The case study used for this research was an academic faculty in one of the higher education institutions in Malaysia. As an academic institution, one of its main activities was promoting research among its staff. To assist its staff in undertaking research, one resource centre was established in the year 2000. Besides becoming the source for academic material, the centre was also responsible for managing the database of the centre. One officer was assigned to manage the database. The database contained information relating to the academic material owned by the centre, borrowed and returned materials, approved research proposals, research in progress, completed research, and publication of the working paper series. An interview with the officer revealed that there were many undetected academic materials. This resulted in havoc with research support process. In addition, the process of updating the faculty research could not be undertaken effectively due to the lack of cooperation from the academic staff.

Thereafter, one discussion was held with the dean of the faculty in order to determine the solution of the above issue. In the meeting, the concept of metaabilities was shared and described. The researchers were also stressed the importance of meta-abilities within the organization and tacit knowledge sharing and externalization. The impact of that process for organizational development was also highlighted. After the meeting, the dean agreed to participate in our research program. Due to the highly developmental nature of the program, the number of the participants was restricted to 12 persons. In this way each delegate was able to receive the high degree of personal attention necessary for the development of meta-abilities.

Based on the above theoretical discussion, the training program was underpinned by the elements of meta-abilities, understanding organizational roles, internal strengths, formal and informal discussion and rational discourse. In short, the program was based on the acquisition of knowledge about an individual's competencies to deal with conflict within the organization. The number of training days for each plant was limited to six days due to the policy of the company on industrial training.

The training program was conducted at the research site due to a convenient factor. The program was conducted face-to-face between the researcher and research participants. The module and program outline were distributed to the research participants on the first day of the program. The program incorporated a variety of features and activities to enhance the learning experience and maximize personal benefits. These included: (1) interactive lectures; (2) syndicate group work; (3) work on live business and IS issues, (4) profiling questionnaires; (5) case studies; (6) one-to-one tutorials or coaching; (7) individual work; and (8) one-day follow up.

On the final day of the program, the participants constructed a comprehensive one-month action plan covering the personal development and organizational change issues. This formed the basis of the progress review. After one month, the researcher met the participants again in order to further develop their seven competency sets by discussing their 
achievements on the targeted actions. Any problems that arose during the seven individual dimensions development period was discussed and tackled at a face-to-face meeting. Two months after the training program, the data collection commenced. The next section describes the findings.

\section{Findings}

Based upon the following discussion, the researcher was interested in building a picture of the levels of development and found: (1) how metaabilities, influencing skills, sharing attitudes and inquisitive tendencies were affected by the elements of understanding organizational roles, internal strengths, formal and informal discussion and rational discourse; (2) what this development then allowed individuals to do with their tacit knowledge; and (3) how the IS was affected by the externalized and shared tacit knowledge. The discussion of the following paragraphs will reflect these three levels of development and follow the structure of the framework in Figure 1.

An overview of the responses indicated change across all the seven sets of the individual development process. With regards to the cognitive skills, $92 \%$ of the interviewed participants indicated improvements:

"Before the program, I didn't know how to solve problems. But after the program, I can now plan my work, know how to solve problems such as, 'we meet our colleagues, have a discussion and find the best solution. It was like giving us guidance in the workplace'."

"After the training program, I manage to solve many problematic tasks successfully and achieve my personal targets. These achievements are backed by strong confidence and awareness and they are undertaken gradually. I feel that what I obtain from the course is complete and critical for individual development. I came back from the course with targets and motivation to achieve them."

Self-knowledge, another meta-ability was also evident. $83 \%$ of the interviewed participants described an increase in self-knowledge as a result of the program. Self-knowledge improved the participants' judgments about how to approach different situations by helping them to distinguish between their personal needs and the needs of the situation and of other people. For example:

"I was highly motivated to be determined and defined in my works. In addition, I was able to prioritize my works that is undertaking a job according to its priority."
"The program influenced my working style that is do not be too rigid or loose but average in nature. Rigidity will give negative impact to the products and loose style will reduce the progress of the work because of its size. Normally, I will not satisfy with my works although other members appreciate them very much. In this situation, I feel that I have achieved the targets."

There were also increases in emotional resilience. $75 \%$ of the interviewed participants described increases in emotional resilience due to the program. For some the focus was on self-discipline:

"I was able to face various behaviors of my staff and cope with them smoothly. I instilled a sense of responsibility to the company among my staff and encouraged them to do the best."

"The program developed my internal and external strengths to fulfill my responsibility in the company. Even from my personal observation, all the participants had showed the similar changes in their commitment and willingness to develop the company. They became less grumpy in the workplace."

In terms of personal drive, $75 \%$ of the interviewed participants described changes equated to it. The development of personal drive was evident in the participants' responses in two ways: in how they viewed their personal approach to tasks; and in what they were able to achieve in their organizations. For example:

"All the virtuous values that were discussed in the program enabled me to have a positive thinking in everything that I do or face. The most significant one was self-disciplined. Being equipped with this element, I am now more objective in dealing with my works."

"Because of the program I turned up in the office early. I have a strong spirit to improve my skills and I taught my subordinates on how to do one task more effectively. When I undertook one task, the outcome was very encouraging and I went back home with the happy feeling."

Improvements in influencing skills, sharing attitudes and inquisitive tendencies were widely reported by all the interviewed participants. $75 \%$ reported changes in general influencing skills; 92\% improvement in sharing attitudes; and $83 \%$ changes in inquisitive tendencies.

The aforementioned empirical results demonstrate the positive development of meta-abilities (cognitive skills, self-knowledge, emotional resilience and personal drive). This showed that the elements of understanding organizational roles, internal strengths, formal and informal discussion and rational discourse are capable of developing meta-abilities. 
Additionally, the above empirical results demonstrate that the high level of meta-abilities was followed by the high level of influencing skills, sharing attitudes and inquisitive tendencies. This showed that all of them were interrelated to each other. Contrastingly, the second level of development of this research was triggered and that is: "what did this development allow individuals to do with their tacit knowledge?"

Improvements in the seven competency sets had helped the participants to formulate their ideas, actions and reactions more clearly, while being much more aware of how these related to others. Improvements in emotional resilience and personal drive helped participants to gain a good reflection by being more assertive, more able to deal with conflict and more objective, yet empathic in coaching and counseling. This situation was experienced by $83 \%$ of the interviewed participants. For example:

"A friend of mine and I are not shy to express our ideas and feeling in the unit meeting anymore. We just say what need to be said and we did it. In fact, most of the unit members appreciated our ideas. Gosh, thanks for your advice."

The above results of ideas, actions, reactions and reflections formulation represent the ability of the participants to externalize and share their tacit knowledge effectively. Implicit in this was that the seven competency sets did provide a platform to the participants to externalize their tacit knowledge in a creative and spontaneous manner. When relating this issue to IS development, $100 \%$ of the participants agreed that there could be a basis for establishing learning-oriented information. In this case, there was a positive relationship between the selfdocumentation of the externalized tacit knowledge with the continuous re-examination and modification of IS contents. It is argued that this type of IS content is capable of promoting OL. The statement made by the center's resource officer was the best example:

"Before the program I was quite reluctant to do the follow-up process for any overdue borrowing or unclear research status. However after the program I became more responsible to check the database and do the follow-up if necessary. I'm not shy anymore to ask for the research status or information relating to the completed research. Thereafter I'm able to update the database effectively."

The above discussions were further supported by the finding where the participants were motivated to share their work progress with others. In this case they were not restricted in asking the resource centre officer for any specific technical assistance. All the participants who participated in this research felt that there had been between $70 \%$ and $100 \%$ success in implementing the personal level of their research plan and all of them shared the research information with others, especially with the resource centre officer. All these enabled the database to get new inputs and as a result, to be able to promote OL within the faculty. This result answered the third level of development of this research, which is that the externalized and shared tacit knowledge led to OL through the updated and progressive IS contents.

From the above discussion it is argued that the development of meta-abilities, influencing skills, sharing attitudes and inquisitive tendencies can assist in developing OL-based IS. This is because they create a willingness among the organizational members to provide knowledge-based inputs to the systems. These inputs in turn enable continuous IS reexamination and modification given the changing reality. Continuously challenging the current "company norm," such systems are expected to prevent the core capabilities of yesterday from becoming core rigidities of tomorrow. By obtaining access to that current "company norm" and internalizing them, organizational members can improve actions through better knowledge and consequently can undertake their tasks effectively the learning process. In short, the conceptual framework used in this research can be applied to practical situations.

\section{Lessons Learned}

Several lessons can be learned from the case study as cited in the previous section. First, organizations should encourage their members to participate in the IS development. The changes in organizational life emphasized more than ever that individual action was central to organizational performance [12]. The "information age" was characterized by individuals taking increased responsibility, becoming more visible and increasing the scope of their contribution. These changes should place a pressure on organizations to harness effectively the abilities and potential of each of their members.

Another important lesson is that the development of meta-abilities, influencing skills, sharing attitudes and inquisitive tendencies was central to the idea of individual participation in the IS development. This is because the organizational reality is not logical, controllable or clear. To deal effectively in this reality requires abilities such as resilience, good judgment and clear thinking. To instill these values, individuals must improve their seven competency sets. 
Finally, the continuous IS development, which is driven by individual participation, enables an effective learning process through knowledge-based database. This in turn enables organization to reduce the organizational operational costs and as a consequence, increase their competitive edge in a highly volatile market.

\section{Conclusion}

This research developed a conceptual framework based on the concepts of tacit knowledge externalization and sharing and meta-abilities that provides the basis of a new perspective on promoting learning within the organization. The processes undertaken in the framework will ensure that the contents of organizational IS are subject to continual re-examination and modification given the changing environment. Continuously challenging the current "company norm," such systems are expected to prevent the core capabilities of yesterday from becoming the core rigidities of tomorrow. By internalizing a system's operations individuals can improve actions through better knowledge and understanding. Therefore the main focus of IS for OL should be toward an individual's meta-abilities development that develops creativity and interpretivity. There should also be an impetus towards creating the right organizational culture and infrastructure that promotes tacit knowledge sharing and externalization within and between employees.

The future directions for this research include the study of the concept of meta-abilities in other IS research areas such as IS effectiveness and implementation. Further areas where this can be used are human-computer interaction, issues pertaining to group coordination and communication and managing the impact of information technologies on organizations planning and control strategies.

\section{References}

[1] Meso, P. and Smith, R., "A resource-based view of organisational knowledge management systems", Journal of Knowledge Management, 2000, 224-234.

[2] Haldin-Herrgard, T., "Difficulties in diffusion of tacit knowledge in organizations", Journal of Intellectual Capital, Emerald, Bradford, 2000, 357-365.

[3] Tsoukas, H., "Do we really understand tacit knowledge?", Knowledge Economy and Society Seminar, London, 2002.
[4] Malhotra, Y., Why knowledge management systems fail? Enablers and constraints of knowledge management in human enterprises, in Koenig, M. E. D. and Srikantaiah, T. K. (Eds), Knowledge management lessons learned: What works and what doesn't, Information Today, 2004.

[5] Augier, M. and Vendelo, M.T., "Networks, cognition and management of tacit knowledge", Journal of Knowledge Management, Emerald, Bradford, 1999, 252261.

[6] Harvey, P. and Butcher, D., "Those who make a difference: Developing businesses through developing individuals", Industrial and Commercial Training, Emerald, Bradford, 1998, 12-15.

[7] Senge, P.M., "The leader's new work: building learning organizations", Sloan Management Review, 1990, 7-23.

[8] Huber, G., "Organisational learning: the contributing processes and literature", Organisation Science, 1991, 88115.

[9] Klimecki, R. and Lassleben, H., "Modes of organizational learning: Indications from an empirical study”, Management Learning, 1998, 405-430.

[10] Nonaka, I. and Takeuchi, H., The knowledge creating company, Oxford University Press, New York, 1995.

[11] Davenport, T.H., De Long, D.W. and Beers, M.C., "Successful knowledge management projects", Sloan Management Review, Winter 1998, 43-57.

[12] Butcher, D., Harvey, P. and Atkinson, S., Developing business through developing individuals, Research Paper, Cranfield School of Management, Cranfield University, 1997.

[13] Schroder, H., Managerial competence: The key to excellence, Kendall/Hunt Publishing, 1989.

[14] Goleman, D., Emotional intelligence. Bloomsbury Publishing, New York, 1995.

[15] Pedler, M., Burgoyne, J. and Boydell, T., A manager's guide to self-development, McGraw-Hill, London, 1994.

[16] Karhu, K., "Expertise cycle - an advanced method for sharing expertise", Journal of Intellectual Capital, Emerald, Bradford, 2002, 430-446.

[17] Earl, M.J. and Hopwood, A.G., From management information to information management, in Lucas, Land, Lincoln, Supper (Eds.), The information systems environment, North-Holland Publishing Company, 1980.

[18] Klein, H. K. and Hirschheim, R., "The rationality of value choices in information systems development", Foundations of Information Systems, 1996 http://www.cba.uh.edu $\sim$ parks/fis/kantpap.htm. 
[19] Choudrie, J. and Selamat, M. H., "Enabling tacit knowledge diffusion through meta-abilities for organisational learning", Proceedings of the tenth americas conference on information systems, New York, 2004, 20522061.

[20] Myers, M. D. and Avison, D. (Eds), Qualitative Research in Information Systems, Sage, London, 2002.

[21] Nachmias, D. and Frankfort-Nachmias, C., Research methods in the social science, 5th ed., St. Martins Press, London, 1996.

[22] Rubin, H. and Rubin, I., Qualitative interviewing: The art of hearing data. Sage, San Diego, 1995.

Figure 1. Meta-abilities for the learning-based information systems

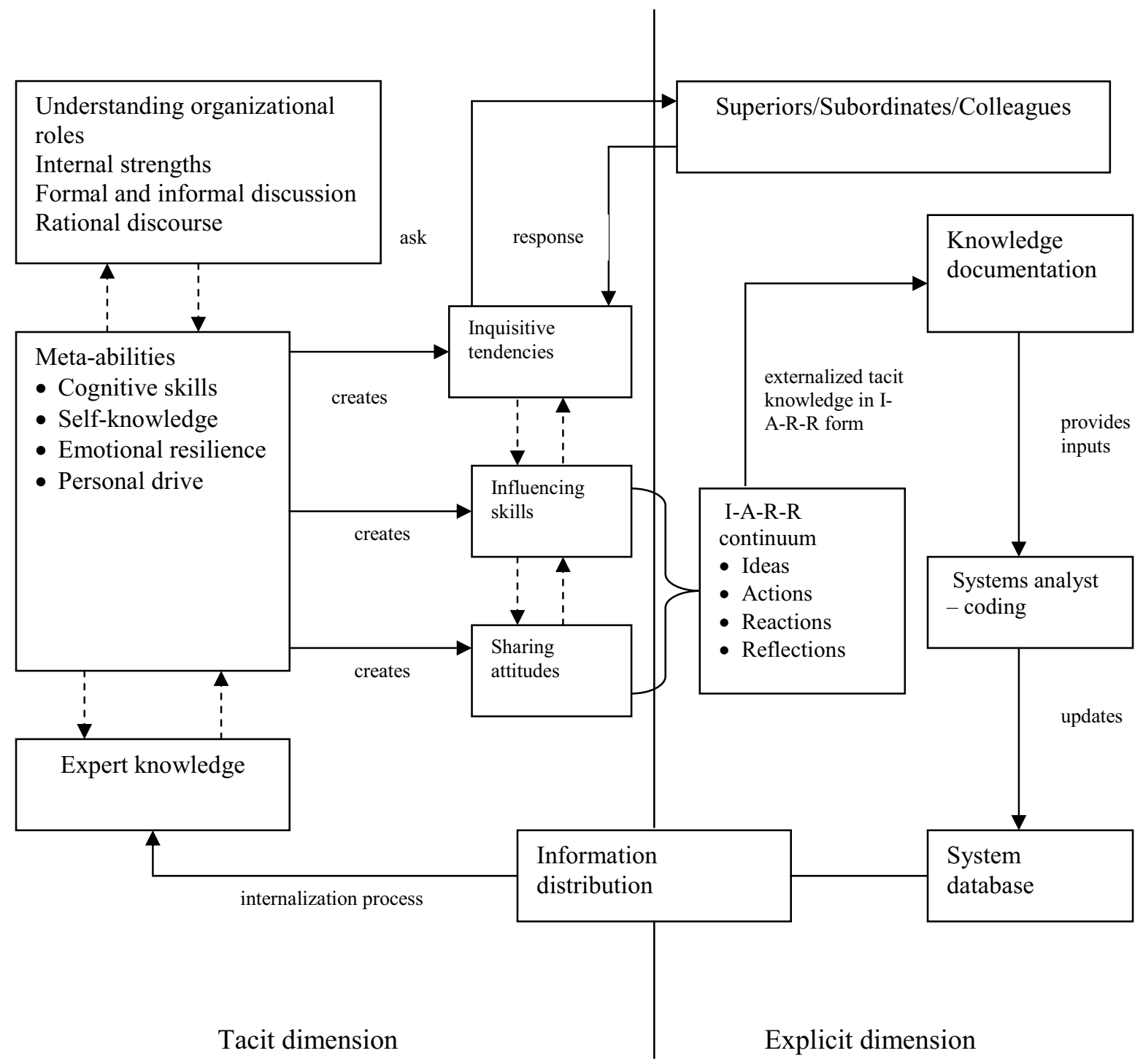

